\title{
Validity and Reliability Study of Two Different Portable Electro- Enzymatic Lactate Analysers
}

\section{İki Farklı Taşınabilir Elektro-Enzimatik Laktat Analiz Cihazının Geçerlilik ve Güvenilirlik Çalışması}

\author{
Halil İbrahim Kaya ${ }^{1}$, Cem Çetin², Duygu Doğuç Kumbul ${ }^{3}$, Mustafa Onur Serbest ${ }^{4}$, Ali Erdoğan ${ }^{5}$ \\ ${ }^{1}$ Sports Medicine Section, Samsun Training and Research Hospital, University of Health Sciences, Samsun, Turkey \\ ${ }^{2}$ Department of Sports Medicine, Faculty of Medicine, Süleyman Demirel University, Isparta, Turkey \\ ${ }^{3}$ Department of Medical Biochemistry, Faculty of Medicine, Süleyman Demirel University, Isparta, Turkey \\ ${ }^{4}$ Sports Medicine Section, Aydin State Hospital, Aydin, Turkey \\ ${ }^{5}$ Sports Medicine Unit, Gloria Sports Arena, Antalya, Turkey
}

\section{H.İ. Kaya \\ 0000-0002-0872-8173 \\ C. Çetin (iD \\ 0000-0002-8151-9554 \\ D. Doğuç Kumbul \\ 0000-0002-3879-9917 \\ M. Onur Serbest (iD) \\ 0000-0001-7827-7999 \\ A. Erdoğan (iD \\ 0000-0001-5279-4744}

Geliş Tarihi/Date Received: 22.05.2019

Kabul Tarihi/Date Accepted: 17.09.2019

Yaym Tarihi/Published Online: 14.01.2020

\section{Yazışma Adresi /}

Corresponding Author:

Halil İbrahim Kaya

Sağlık Bilimleri Üniversitesi, Samsun Eğitim ve Araştırma Hastanesi, Spor Hekimliği, Samsun, Turkey

E-mail:

sporhekimi8@gmail.com

(C2020 Türkiye Spor Hekimleri Derneği. Tüm hakları saklıdır.

\section{ABSTRACT}

Objectives: The purpose of this study was to evaluate the reliabilities of the Biosen $C$ Line (BCL) laboratory and Lactate Scout (LS) hand-held portable lactate analyser within a wide range lactate concentration. $\mathrm{LS}$ analyser was compared to the $\mathrm{BCL}$ analyser (reference method) to evaluate its validity.

Materials and methods: Blood samples were taken during an incremental treadmill test under laboratory conditions. In order to evaluate reliability, 99 blood samples with lactate concentrations changed between 0.8-11.1 mM were measured twice.

Results: For the LS analyser, intraclass correlation coefficient (ICC) was 0.994 ; typical error of measurement $(\mathrm{TE})$ and coefficient of variation $(\mathrm{CV})$ were $0.200 \mathrm{mM}$ and $2.95 \%$, respectively. For the $\mathrm{BCL}$ analyser, ICC was 1.000 ; TE and CV were $0.044 \mathrm{mM}$ and $0.50 \%$, respectively. LS hand-held portable- and BCL laboratory analysers' reliability results show perfect accordance. In order to evaluate LS analyser reliability, 99 blood samples with lactate concentrations between 0.8-11.1 mM were also measured, giving a high validity coefficient of 0.976 . Validity was also separately assessed for the three sample ranges of $<2.5 \mathrm{mM}, 2.5-5.0 \mathrm{mM}$ and $>5.0 \mathrm{mM}$, yielding ICC values of 0.862 , 0.903 and 0.783 , respectively. Comparing with the Bland \& Altman method, LS and reference method mean lactic acid concentration difference was $-0.097 \mathrm{mM}$, and limits of agreement -1.342 and $1.147 \mathrm{mM}$.

Conclusion: The results of the study revealed that the LS analyser has high validity, however at concentrations higher than $5.0 \mathrm{mM}$, its measures are found significantly lower than those of the reference method.

Keywords: Lactate analysis, validity, reliability

\section{öz}

Amaç: Bu çalışmanın amacı laboratuvar analizörü olan Biosen C Line (BCL) ile bir el analizörü olan Lactate Scout'un (LS) geniş bir kan laktat derişim aralığında güvenirliğini değerlendirmektir. Ayrıca LS analizörünü, BCL analizörü (referans yöntem) ile karşılaştırarak geçerliliğini değerlendirmektir.

Gereç ve Yöntemler: Kan örnekleri laboratuvar şartlarında, koşu bandı ile şiddeti giderek artan egzersiz testi sırasında alındı. LS ve BCL analizörlerinin güvenirliği için kan laktat derişimi 0.8-11.1 mM aralığında değişen 99 örnekte test-tekrar test ölçümleri yapıldı. 


\begin{abstract}
Bulgular: LS analizörü için sınıf içi korelasyon kat sayıSı (SKK) 0.994, tipik hata (TH) $0.200 \mathrm{mM}$, varyasyon katsayısı (VK) \%2.95'di. BCL analizörü için SKK 1.000, TH 0.044 mM, VK \%0.50'ydi. Her iki analizörün de Güvenilirlik çalışması sonuçları mükemmel uyum gösterdi. LS analizörünün geçerliliği için 0.8-11.1 mM aralığında değişen 99 örnek aynı anda hem LS hem de BCL analizörü ile ölçüldü. LS analizörü yüksek geçerlilik katsayısına (0.976) sahipti. Geçerlilik analizleri <2.5 mM, 2.5-5.0 mM ve >5.0 mM kan laktat derişim aralıkları için ayrı ayrı değerlendirildi. SKK sırasıyla $0.862,0.903$ ve 0.783 'dü. LS ve referans yöntem ölçümleri Bland \&Altman yöntemi ile karşılaştırıldığında laktat konsantrasyon değerlerinin farklarına ait ortalama $-0.10 \mathrm{mM}$, uyum sınırları -1.34 ve $1.15 \mathrm{mM}$ olarak bulundu.

Sonuç: Bu çalışmanın bulguları LS analizörünün yüksek geçerliliğe sahip olduğunu göstermekle birlikte, >5.0 mM konsantrasyon değerlerinde, referans yöntemle ölçülen değerlerden sistematik olarak önemli derecede düşük bulundu.
\end{abstract}

Anahtar sözcükler: Laktat analizi, geçerlilik, güvenilirlik

Available at: http://journalofsportsmedicine.org and http://dx.doi.org/10.5152/tjsm.2020.170

Cite this article as: Kaya HI, Cetin C, Doguc Kumbul D, Serbest MO, Erdogan A. Validity and reliability study of two different portable electro-enzymatic lactate analysers. Turk J Sports Med. 2020;55(2):138-47.

\section{GíRiş}

Antrenmanda ya da egzersiz reçetelendirilmesinde egzersiz yoğunluğunun belirlenmesi ve uygun antrenman yükleri ile çalışmak önem taşımaktadır. Bu yüklerin saptanmasında koşu hızı, kalp atım hızı, kan laktat konsantrasyonu ya da oksijen tüketimi benzeri fizyolojik ölçümlerden yararlanılmaktadır (1). Uzun süreli dayanıklılık antrenmanlarının etkileri ile ilgili çalışmalarda antrenmanın maksimum oksijen tüketimi ve dayanıklılık performansını önemli ölçüde değiştirdiği gösterilir. Dayanıklılık performansı oksijen tüketimi ile ilişkili olmakla birlikte, belirli kan laktat derişimleri ile tanımlanan metabolik hız ile daha kuvvetli ilişkilidir (2).

Egzersiz testleri, şiddeti kademeli olarak arttırılan egzersize yanıt olarak; kalp atım hızı, kan laktat konsantrasyonu, oksijen tüketimi gibi fizyolojik değişimlerin gözlenmesi temeline dayanır. Takım ya da bireysel sporlarda dayanıklılık egzersizine verilen metabolik yanıtların değerlendirilmesinde, uygun antrenman yoğunluğunun belirlenmesinde, performans gelişimi izlenmesinde, farklı hastalık gruplarında uygun egzersiz yoğunluğunun reçetelendirilmesinde yaygın olarak kullanılmaktadır (3).

Teknolojik gelișmelere paralel olarak laboratuvar ortamındaki ölçüm sistemleri kadar duyarlı, güvenilir ve geçerli, hem laboratuvar hem de saha koşullarında çalışmaya uygun taşınabilir analizörler kullanılmalıdır. Bununla birlikte son yıllarda kullanımı daha da kolay olan ve çok az kan örneği ile hızlı bir şekilde kan laktat derişi- mi ölçümü yapabilen el analizörleri yaygın olarak kullanılmaya başlanmıştır.

Lactate Scout (SensLab GmbH, Almanya) enzimatik amperometrik yöntemle analiz yapan el tipi taşınabilir bir laktat ölçüm cihazıdır. Cihaz, 15 saniyelik sürede tek kullanımlık test stripleri ile yaklaşık $0.5 \mu \mathrm{L}$ kapiller kan örneğinden ölçüm yapabilmektedir. Lactate Scout (LS) üretici firma verilerine göre $0.5-25.0 \mathrm{mM}$ aralığında ölçüm yapabilmektedir.

Biosen C Line (BCL) kan laktat analizörü (SensLab GmbH, Almanya) enzimatik amperometrik sensör teknolojisi ile ölçüm yapan laboratuvar tipi bir analiz cihazıdır. Kan, plazma ya da serum örneklerinde ölçüm yapabilmekte ve $20 \mu \mathrm{L}$ örnek alımı yeterli olmaktadır. BCL üretici firma verilerine göre $0.5-40.0 \quad \mathrm{mM}$ ölçüm aralığındadır, tek bir ölçüm 20-45 saniye sürede tamamlanmaktadır. Referans yöntem olarak Roche Hitachi Cobas 6000, antikoagülan olarak lityum heparin kullanılan, buzağı serumları ile $8.0 \mathrm{mM}$ değerine kadar yapılan bir geçerlilik çalışmasında BCL için $r 0.99(\mathrm{p}<0.01)$, Bland Altman yöntemi kullanılarak elde edilen uyum sınırları ise 0.16 ve -0.96 olarak verilmektedir (4).

$\mathrm{Bu}$ çalışmanın amacı laboratuvar temelli taşınabilir bir analizör olan BCL ile el tipi laktat ölçüm cihazı LS'nin şiddeti kademeli olarak artan egzersiz testi sırasında toplanan örneklerde test-tekrar test şeklinde yapılan tekrarlı ölçümlerle güvenirliğini belirlemektir. Ayrıca LS anali- 
zörünü BCL analizörü (referans yöntem) ile karşılaştırarak geçerliliğini değerlendirmektir.

\section{GEREÇ ve YÖNTEM}

\section{Araştırma Grubu}

$\mathrm{Bu}$ çalışma protokolü ve klinik metod 7.3.2012 tarih ve 14 numaralı Süleyman Demirel Üniversitesi Tıp Fakültesi İlaç Dışı Klinik Araştırmaları Etik Kurulu onayı ile Süleyman Demirel Üniversitesi'nde yapıldı. Çalışmaya üniversite öğrencisi, aktif spor yapan, yaşları 18-22 (ortalama 20.0 \pm 1.5 ) arasında değișen gönüllü 10 erkek sporcu alındi.

\section{Egzersiz Testi ve Kan Örneklerinin Alınması}

Egzersiz testi laboratuvar koşullarında koşu bandında (StarTrac Pro, ABD) yapıldı. Egzersiz testine her $3 \mathrm{dk}$ 'da bir kan örneği almak için $60 \mathrm{~s}$ ara verildi. Egzersiz testi başlangıç hızı 7.0 $\mathrm{km} / \mathrm{h}$, eğim ise $0^{\circ}$ olarak belirlendi ve eğim test süresince sabit tutuldu. Koşu hızı her 3 dk'da bir, kan örneği almak için verilen aranın ardından $1.0 \mathrm{~km} / \mathrm{h}$ arttırıldı. Egzersiz testi sporcular tükenene dek sürdürüldü. Farklı bölgelerden (venöz plazma, venöz kan ve kapiller kan), farklı yöntemlerle alınan örneklerde kan laktat değerleri karşılaştırıldığında anlamlı farklar olduğu bilinmektedir. Bu çalışmada laktat analizörleri değerlendirildiğinden, egzersiz testinde ve öncesinde kan örneklerinin alımını kolaylaştırmak, alınan örneklerde standardizasyonu sağlayabilmek amacı ile antekübital bölgedeki periferik venlere branül yerleştirildi ve deneyimli bir sağlık profesyoneli tarafından kan örnekleri alındı.

\section{Kan Örneklerinin Değerlendirilmesi}

Her kan örneğinin (0.5 $\mu \mathrm{L}$ x 2) $1.0 \mu \mathrm{L}$ 'si $15 \mathrm{~s}$ içinde LS taşınabilir laktat analizöründe kullanıldı. LS'nin Güvenilirlik çalışması için farklı iki strip kullanılarak $30 \mathrm{~s}$ içinde farklı iki laktat analizi yapıldı. Striplerin kontrolü için her yeni kutu standart kontrol çözeltisi ile test edildi. Sonuçlar normal sınırlardaydı.

Kan örneğinin $20 \mu$ L'si cam kapiller tüp (bir uçtan diğer uca dolacak şekilde) içerisine alınarak, $1.0 \mathrm{ml}$ laktat hemoliz çözeltisi içeren tüpe bırakıldı ve tüpün ağzı kapatılıp ters-düz edile- rek, kan örneğinin laktat hemoliz çözeltisiyle karışması sağlandı. Her sporcu için egzersiz testinin sona ermesiyle birlikte laktat hemoliz çözeltisi içerisine bırakılan örneklerin, taşınabilir laktat analizörü BCL ile laktat analizi yapıldı. BCL'nin Güvenilirlik çalışması için laktat hemoliz çözeltisi içerisine alınan örnekler ard arda iki kez çalışıldı. BCL analizörü her çalıştırıldığında ve her 10 örneğin analizinden sonra analizörün kalibrasyonu yapıldı. Kalibrasyon sırasında 12.0 mM'lik standart çözelti kullanıldı. Her kalibrasyonu takiben 2.0 ve 15.0 mM'lik kontrol çözeltileri ile kontrol ölçümleri yapıldı. Bu ölçüm sonuçları normal aralıktaydı.

\section{İstatistiksel Analiz}

İstatistiksel değerlendirme, SPSS 22.0 paket programı kullanılarak yapıldı. Analizörlerin güvenirliğini ve BCL analizörü referans yöntem alınarak LS analizörünün geçerliliğini göstermek için sınıf içi korelasyon katsayısı (SKK), Pearson korelasyon katsayısı, regresyon analizi ve Bland \& Altman yöntemleri kullanıldı. Anlamlılık düzeyi olarak p $<0.05$ kullanıldı. Tekrarlı ölçümler için tipik hata (TH) ve varyasyon katsayısı (VK) değerleri Microsoft Excel yazılımı ile belirlendi. İki ölçüm arasındaki farkların standart sapması "SD" olarak tanımlandığında $\mathrm{TH}=\mathrm{SD} / \sqrt{2}$ formülü ile hesaplandı. Logaritmik dönüşüm yapılmış veriler ile hesaplanan $\mathrm{TH}$ değeri " $s$ " olarak tanımlandığında ise $\mathrm{VK}=100\left(\mathrm{e}^{\mathrm{s}}-1\right)$ formülü ile hesaplandı (5).

\section{BULGULAR}

\section{Güvenilirlik Analizi}

LS1, LS2, BCL1 ve BCL2 test-tekrar test şeklinde yapılan ölçümlerin tanımlayıcı bilgileri Tablo 1 'de; güvenirliğine ilişkin istatistiksel bulgular, regresyon sabiti ve regresyon katsayılarının \%95 güven aralıkları Tablo 2'de gösterilmektedir. LS analizörü sonuçlara göre, regresyon sabiti 0.04'tür ve güven aralığı 0 değerini kapsamakta, regresyon kat sayısı 1.008'dir ve güven aralığı 1 değerini kapsamaktadır. Tüm ölçümler için regresyon doğrusunu $\mathrm{y}=1.008 \mathrm{x}+0.04$ denklemi tanimladi. $\mathrm{R}=0.989, \mathrm{R}^{2}=0.978, \mathrm{~F}=4249$, $\mathrm{TH}=0.401, \mathrm{VK}=\% 5.98$ 'dir. Bu denklemde " $\mathrm{y}$ " LS2'yi, "x" ise LS1'i ifade etmektedir. Bu koşul- 
larda, LS analizörü ile yapılan tekrarlı ölçümlerde kan laktat derişim değerleri arasında sistematik ve orantısal yanlılık gözlenmediği sonucuna varıldı. Şekil 1'de ölçümler arasındaki ilişki gösterildi ve bu grafikte LS analizörü ile testtekrar test şeklinde alınan verilerin (kan laktat derişimi) birbirleri ile uyumlu olduğu gözlendi.

Benzer şekilde, BCL için tüm ölçümler için regresyon doğrusunu $\mathrm{y}=0.998 \mathrm{x}+0.019$ denklemi tanımladı. Burada da " $y$ " BCL2' $y i$, " $x$ " ise BCL1' $\mathrm{i}$ ifade etmektedir. $\mathrm{R}=1.000, \mathrm{R}^{2}=0.999, \mathrm{~F}=133521$, $\mathrm{TH}=0.087, \mathrm{VK}=\% 1.01$ 'dir. BCL analizörü ile yapılan tekrarlı ölçümlerde de kan laktat derişim değerleri arasında sistematik ve orantısal yanlılık gözlenmediği sonucuna varıldı. Şekil 1'de ölçümler arasındaki ilişski gösterildi ve bu grafikten BCL analizörü ile test-tekrar test şeklinde alınan verilerin birbirleri ile uyumlu olduğu gözlendi.

Tablo 1. Lactate Scout (LS) ve Biosen C Line (BCL) laktat analizörleri ile elde edilen ikișer set tam verinin tanımlayıcı istatistikleri

\begin{tabular}{lllll}
\hline Ölçüm & Ortalama & SS & SOH & Min/Maks \\
\hline LS1 & 3.15 & 1.86 & 0.19 & $1.2 / 9.0$ \\
LS2 & 3.18 & 1.89 & 0.19 & $1.2 / 10.1$ \\
BCL1 & 3.25 & 2.30 & 0.23 & $0.8 / 11.1$ \\
BCL2 & 3.26 & 2.29 & 0.23 & $0.8 / 11.1$ \\
\hline
\end{tabular}

Değerler mM; $n=99 ;$ SS: standart sapma; SOH: standart ortalama hata

Tablo 2. Değişik konsantrasyon aralıklarında Lactate Scout (LS) ve Biosen C Line (BCL) analizörlerinin güvenilirlik istatistik sonuçları

\begin{tabular}{|c|c|c|c|c|c|c|c|c|c|}
\hline & & $\mathrm{a}$ & $\% 95 \mathrm{GA}$ & $\mathrm{b}$ & $\% 95 \mathrm{GA}$ & $\mathrm{R}^{2}$ & SKK & $\mathrm{TH}$ & VK \\
\hline \multirow{4}{*}{ 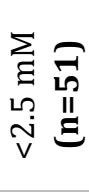 } & LS1 & \multirow{2}{*}{0.217} & 0.486 & \multirow{2}{*}{0.899} & 1.046 & \multirow{2}{*}{$0.754^{*}$} & \multirow{2}{*}{$0.928 *$} & \multirow{2}{*}{0.139} & \multirow{2}{*}{3.36} \\
\hline & LS2 & & -0.530 & & 0.752 & & & & \\
\hline & BCL1 & \multirow{2}{*}{0.010} & 0.043 & \multirow{2}{*}{1.002} & 1.022 & \multirow{2}{*}{$0.995 *$} & \multirow{2}{*}{ 0.999* } & \multirow{2}{*}{0.022} & \multirow{2}{*}{0.56} \\
\hline & BCL2 & & -0.024 & & 0.983 & & & & \\
\hline \multirow{4}{*}{ 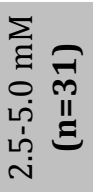 } & LS1 & \multirow{2}{*}{-0.097} & 0.420 & \multirow{2}{*}{1.030} & 1.174 & \multirow{2}{*}{$0.881^{*}$} & \multirow{2}{*}{$0.967^{*}$} & \multirow{2}{*}{0.203} & \multirow{2}{*}{2.62} \\
\hline & LS2 & & -0.613 & & 0.886 & & & & \\
\hline & BCL1 & \multirow{2}{*}{0.045} & 0.106 & \multirow{2}{*}{0.992} & 1.008 & \multirow{2}{*}{$0.998^{*}$} & \multirow{2}{*}{$0.999 *$} & \multirow{2}{*}{0.034} & \multirow{2}{*}{0.38} \\
\hline & BCL2 & & -0.016 & & 0.975 & & & & \\
\hline \multirow{4}{*}{ 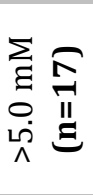 } & LS1 & \multirow{2}{*}{-0.942} & 0.540 & \multirow{2}{*}{1.150} & 1.373 & \multirow{2}{*}{$0.889^{*}$} & \multirow{2}{*}{$0.963^{*}$} & \multirow{2}{*}{0.203} & \multirow{2}{*}{2.12} \\
\hline & LS2 & & -2.425 & & 0.927 & & & & \\
\hline & BCL1 & \multirow{2}{*}{0.099} & 0.433 & \multirow{2}{*}{0.988} & 1.032 & \multirow{2}{*}{$0.994^{*}$} & 0 998* & 0.084 & 0.49 \\
\hline & BCL2 & & -0.235 & & 0.945 & & $0.998^{\circ}$ & 0.084 & 0.49 \\
\hline & LS1 & 0.040 & 0.116 & 1.008 & 1.038 & $0.978^{*}$ & $0.994 *$ & 0.200 & 2.95 \\
\hline तु & LS2 & 0.070 & -0.108 & 1.000 & 0.977 & & & & \\
\hline & BCL1 & 0019 & 0.040 & 0998 & 1.004 & 0 999* & $1000 *$ & 0044 & 050 \\
\hline & BCL2 & 0.019 & -0.030 & 0.998 & 0.993 & 0.999 & 1.000 & 0.044 & 0.30 \\
\hline
\end{tabular}

a: regresyon sabiti; b: regresyon katsayısı; GA: güven aralığı; $R^{2}$ : Pearson korelasyon kat sayısının karesi; SKK: sınıf içi korelasyon kat sayısl; TH: tipik hata; VK: Varyasyon katsayısı (\%); *: p<0.001 


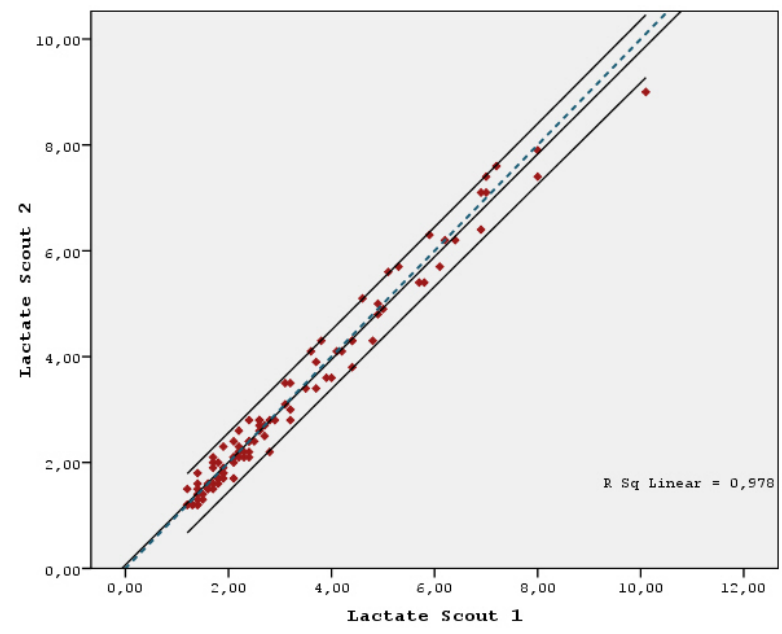

Şekil 1. Lactate Scout 1-2 ölçümleri (tüm, $n=99$ ) arasındaki ilişki grafiği. Orta çizgi: regresyon doğrusu, alt ve üst çizgiler: $\% 95$ güven aralıkları, kesikli çizgi: eşitlik doğrusu (x=y).

Şekil 2'de BCL analizörü için görüldüğü üzere, Bland \& Altman saçılım grafiğinde test-tekrar test şeklinde yapılan tüm ölçüm verileri ortalamalarına karşı fark değerlerine ilişkin noktaların önemli kısmı uyum sınırları içinde olduğu için, kan laktat derişimleri ortalamaları ile farklar arasında ilişki olmadığı sonucuna varılmaktadır. İlişki olmaması her iki analizör ile yapılan ölçümler arasında sabit hata (varyans) ile ölçüm yapıldığını gösterir. Bu durum <2.5 $\mathrm{mM}, 2.5-5.0 \mathrm{mM}$ ve $>5.0 \mathrm{mM}$ laktat derişimleri için de geçerli bulundu. BCL analizörü ile ölçülen değerlerin farklarına ait ortalama $0.013 \pm 0.061$ mM idi. Bland ve Altman yöntemi kullanılarak elde edilen \pm 1.96 SD uyum sinırları 0.135 ve 0.107 olarak bulundu. Bu durum BCL1 değerlerinin BCL2 değerlerinden $0.135 \mathrm{mM}$ büyük, $0.107 \mathrm{mM}$ küçük olabileceği anlamınadır. $\mathrm{R}^{2}=0.002$; regresyon denklemi $\mathrm{y}=0.0012 \mathrm{x}+$ 0.02 'dir. LS analizörü ile ölçülen değerlerin farklarına ait ortalama ise $0.028 \pm 0.283 \mathrm{mM}$ idi. Bland-Altman yöntemi kullanılarak elde edilen \pm 1.96 SD uyum sinırları 0.583 ve -0.526 ve olarak bulundu. Bu sonuca göre, LS1 değerleri, LS2 değerlerinden $0.583 \mathrm{mM}$ büyük, 0,526 mM küçük olabilmektedir. $\mathrm{R}^{2}=0.016$; regresyon denklemi $y=0.02 x+0.03$ 'tür.

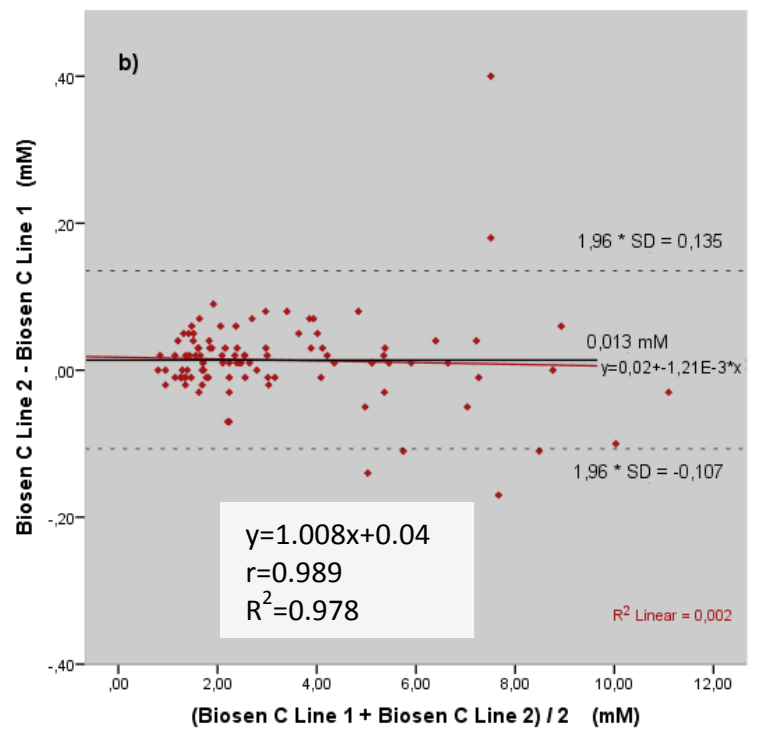

Şekil 2. Test-tekrar test şeklinde ölçülen tüm kan (n=99) laktik asit derişim ortalamaları ile Biosen C Line analizörü ölçüm farkları arasındaki ilişkileri ve tutarlılık sınırlarını gösteren Bland-Altman saçlım grafiği

\section{Geçerlilik Analizi}

LS analizörünün geçerlilik çalışması için BCL analizörü referans olarak kullanıldı. Geçerlilik çalışması için kullanılan verilerin istatistiksel bulguları ve regresyon sabiti ile regresyon katsayılarının \% 95 güven aralıkları Tablo 3'de gösterildi. $\mathrm{Bu}$ sonuçlara göre, regresyon sabiti 0.587 'dir ve güven aralığı 0 değerini kapsamamakta, regresyon kat sayısı 0.789 'dur ve güven aralığı 1 değerini kapsamamaktadır. Bu koşullarda, iki analizör ile yapılan ölçümlerde elde edilen kan laktat değerleri arasında, hem sistematik hem de orantısal yanlılık gözlendiği sonucuna varılmaktadır. $\mathrm{y}=1.205 \mathrm{x}-0.547$ denklemi regresyon doğrusunu tanımlar. $\mathrm{R}^{2}=0.951$, $\mathrm{F}=1875$, kestirimin standart hatası (KSH) 0.512 'dir. Bu denklemde "y" BCL'yi, " $x$ " ise LS'yi tanımlar. Regresyon denklemi yardımıyla LS analizörü ile elde edilen değerler kullanılarak referans yöntem olan BCL değerleri tahmin edilebilirse de, bu durum iki analizör arasında mutlak uyumun iyi bir düzeyde olmadığını gösterir. Şekil 3'de LS ve BCL ölçümleri arasındaki ilişki gösterilmektedir ve eşitlik doğrusu ile regresyon 
doğrusu birbirinden farklıdır. İki analizör ile ölçülen kan laktat değerlerine ilişkin SKK verileri değerlendirildiğinde her iki analizörün ölçüm- leri arasında mükemmel uyum olduğundan söz edilebilir.

Tablo 3. Değişik konsantrasyon aralıklarında Biosen C Line analizörü referansına göre Lactate Scout analizörünün geçerlilik çalışmasına ilişkin istatistik sonuçları

\begin{tabular}{|c|c|c|c|c|c|c|c|c|}
\hline Derişim & Analizör & $\mathbf{a}$ & $\% 95$ GA & $\mathrm{b}$ & $\% 95$ GA & $\mathbf{R}^{2}$ & SKK & KSH \\
\hline \multirow{2}{*}{$\begin{array}{l}<2.5 \mathbf{m M} \\
(\mathrm{n}=51)\end{array}$} & LS & \multirow{2}{*}{-0.071} & -0.446 & \multirow{2}{*}{0.967} & 0.762 & \multirow{2}{*}{$0.647^{*}$} & \multirow{2}{*}{$0.862^{*}$} & \multirow{2}{*}{0.272} \\
\hline & BCL & & 0.762 & & 1.173 & & & \\
\hline \multirow{2}{*}{$\begin{array}{l}2.5-5.0 \mathrm{mM} \\
(\mathrm{n}=31)\end{array}$} & LS & \multirow{2}{*}{-0.575} & -1.527 & \multirow{2}{*}{1.171} & 0.906 & \multirow{2}{*}{$0.738^{*}$} & \multirow{2}{*}{$0.903^{*}$} & \multirow{2}{*}{0.535} \\
\hline & BCL & & 0.376 & & 1.436 & & & \\
\hline \multirow{2}{*}{$\begin{array}{l}>5.0 \mathrm{mM} \\
(\mathrm{n}=17)\end{array}$} & LS & \multirow{2}{*}{-0.765} & -3.714 & \multirow{2}{*}{1.255} & 0.811 & \multirow{2}{*}{$0.707^{*}$} & \multirow{2}{*}{$0.783^{*}$} & \multirow{2}{*}{0.895} \\
\hline & BCL & & 2.185 & & 1.699 & & & \\
\hline \multirow{2}{*}{$\begin{array}{l}\text { Total } \\
(\mathrm{n}=99)\end{array}$} & LS & \multirow{2}{*}{-0.547} & -0.749 & \multirow{2}{*}{1.205} & 1.149 & \multirow{2}{*}{$0.951^{*}$} & \multirow{2}{*}{$0.976^{*}$} & \multirow{2}{*}{0.512} \\
\hline & BCL & & -0.346 & & 1.260 & & & \\
\hline
\end{tabular}

a: regresyon sabiti; b: regresyon katsayısl; GA: güven aralı̆ğ; R2: Pearson korelasyon kat sayısının karesi; SKK: sınıf-içi korelasyon kat sayısı; KSH: kestirimin standart hatası; *: p<0.001

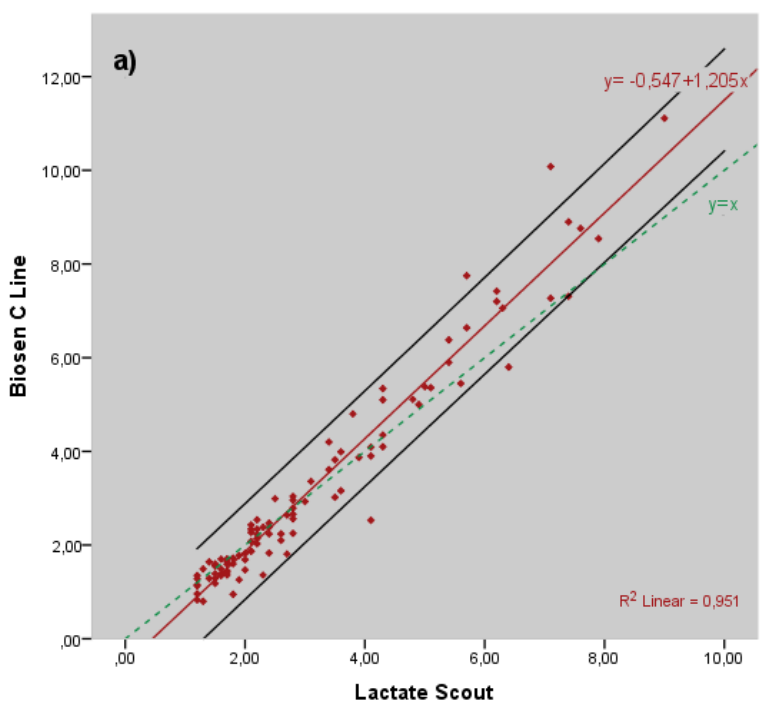

Şekil 3. Lactate Scout ve Biosen C Line tüm ölçümleri (n=99) arasındaki ilişki grafiği. Ortadaki çizgi: regresyon doğrusu; alt ve üst çizgiler: regresyon doğrusunun \%95 güven aralıkları; kesikli çizgi: eşitlik doğrusu ( $\mathrm{x}=\mathrm{y})$.

LS analizörünün geçerliğine yönelik istatistik analizleri değişik konsantrasyon aralıklarında da değerlendirildi. Böylece $<2.5$ mM 51 örneğin kan laktat sonuçlarına göre, regresyon denklemi $\mathrm{y}=0.967 \mathrm{x}-0.071 ; \quad \mathrm{R}^{2}=0.647, \quad \mathrm{~F}=89.677 \quad$ ve $\mathrm{KSH}=0.272$ oldu. Bir sonraki 2.5-5.0 mM aralığındaki 31 örneğin sonuçlarına göre regresyon denklemi $\mathrm{y}=1.171 \mathrm{x}-0.575 ; \mathrm{R}^{2}=0.738$, $\mathrm{F}=81.690$ ve $\mathrm{KSH}=0.393$ idi. Son olarak $>5.0 \mathrm{mM}$ 17 örneğin kan laktat sonuçlarına göre, regresyon denklemi $\mathrm{y}=1.255 \mathrm{x}-0.765 ; \quad \mathrm{R}^{2}=0.707$, $\mathrm{F}=36.266$ ve $\mathrm{KSH}=0.893$ olarak gerçeklești. Buna göre $<2.5 \mathrm{mM}$ ve $>5.0 \mathrm{mM}$ laktat derişimlerine ilişkin SKK, Pearson korelasyon katsayısı, KSH ve varyasyon katsayısı olarak \% KSH verileri değerlendirildiğinde LS ve referans BCL ölçümleri arasında orta düzey; $2.5-5.0 \mathrm{mM}$ aralığında ise yüksek uyum olduğundan söz edilebilir (Tablo 3).

Şekil 4'de görülebileceği üzere Bland \& Altman saçılım grafiğindeki LS ve BCL analizörleri ile yapılan kan laktat derişimlerinin ortalamaya karşı fark değerlerine ilişkin noktaların önemli kısmı uyum sınırları içindedir. Tüm kan laktat düzeylerine ilişkin ortalamalar ve farklar arasında ilişkili olduğu $\left(\mathrm{R}^{2}=0.480\right)$, rastlantısal dağılmadığı ve ortalamalar arttıkça farkların azaldığı gözlenmektedir. Konsantrasyon değerlerinin farklarına ait ortalama $-0.097 \mathrm{mM}$, standart sapma ise 0.635 'dir. Bland ve Altman yöntemi kullanılarak elde edilen \pm 1.96 SD uyum 
sinırları 1.147 ve -1.342 olarak saptandı. Buna göre, LS analizörü ile ölçülen kan laktat değerleri, BCL ile ölçülen kan laktat değerlerinden 1.147 mM büyük, $1.342 \mathrm{mM}$ küçük olabilir. Regresyon denklemi $y=-0.21 \mathrm{x}+0.58$ şeklinde gerçekleşti.

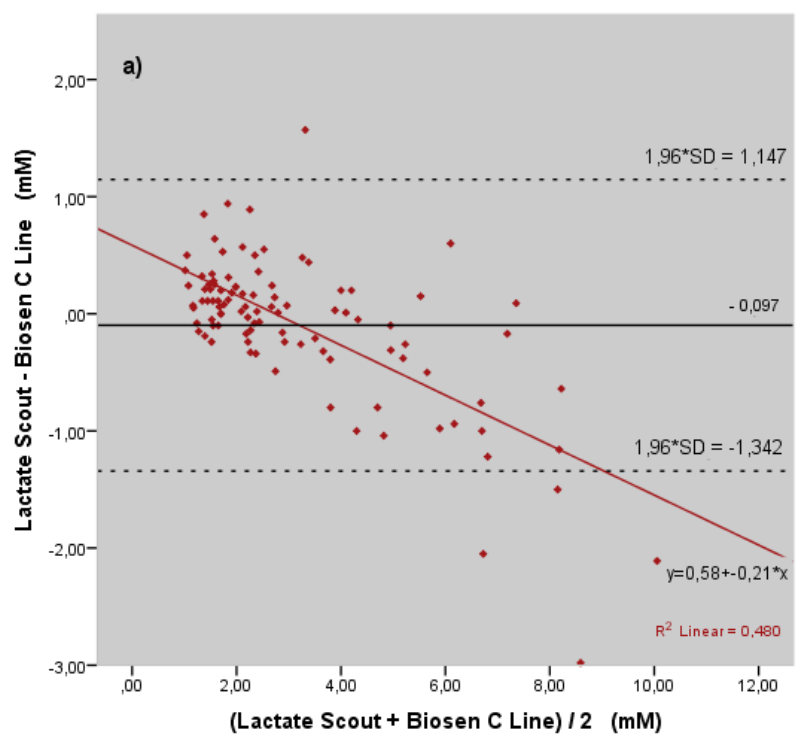

Şekil 4. Lactate Scout ve Biosen C Line analizörleri kullanılarak ölçülen tüm $(n=99)$ kan laktat örnekleri ortalamaları ile ölçüm farkları arasındaki ilişkileri ve tutarlılık sınırlarını gösteren Bland \& Altman saçılım grafiği

Ancak, $<2.5 \mathrm{mM}$ ve $2.5-5.0 \mathrm{mM}$ aralığı kan laktat konsantrasyonları için Bland \& Altman saçılım grafiğinde her iki analizör ile yapılan laktat ölçümleri ortalamalarına karşı fark değerlerine ilişkin noktaların önemli kısmı uyum sınırları içinde olduğundan, kan laktat ortalamaları ve farkları arasında ilișki olmadığı sonucuna varılır. İlișki yokluğu LS analizörünün bu aralıklarda kan laktat değerleri için sabit hata (varyans) ile ölçüm yaptığını gösterir $(\mathrm{Bu}$ iki aralık için sırasıyla fark ortalamaları 0.153 ve $-0.104 \mathrm{mM}$, $\mathrm{R}^{2}=0.019$ ve $0.144, \pm 1.96 \mathrm{SD}$ sinırları 0.688 /0.381 ve $0.927 /-1.136 \mathrm{mM}$, regresyon denklemleri $\mathrm{y}=-0.09 \mathrm{x}+0.32$ ve $\mathrm{y}=-0.27 \mathrm{x}+0.87)$. Buna karşın, $>5.0 \mathrm{mM}$ laktat değerleri için Bland \& Altman saçılım grafiğindeki LS ve BCL analizörleri ile yapılan kan laktat ölçüm ortalamalarına karşı fark değerlerine ilişkin noktaların önemli kısmı uyum sınırları içinde olup, kan laktat ortalamaları ve farkları arasında zayıf bir ilişki olduğu $\left(R^{2}=0.374\right)$, rastlantısal dağılmadığı ve farkların azaldığı gözlenmektedir. Derişim farklarına ilişkin ortalama $-0.878 \mathrm{mM}, 1.96 \mathrm{SD}$ uyum sinırları 0.864 ve $-2.621 \mathrm{mM}$, regresyon denklemi $y=-0.41 x+1.98$ olarak hesaplandl.

\section{TARTIŞMA}

Sporcularda en uygun antrenman yoğunluğunun belirlenmesi ve izlenmesinde, dayanıklılık egzersizlerine verilen metabolik yanıtların değerlendirilmesinde, ayrica farklı hastalıklarda uygun egzersiz yoğunluğunun reçetelendirilmesinde kan laktat düzeylerinden yaygın olarak yararlanılır. Test ortamındaki çeşitli faktörler kan laktat derişimlerini etkilediği için ölçümlerin yapıldığı test ortamları dikkatlice düzenlenmelidir (6). Günümüzde hem laboratuvar hem de saha koșullarında çalıșmaya uygun farklı analiz cihazları geliștirilmiş olmakla birlikte; bu çalışmada BCL laboratuvar analizörü ile el tipi laktat ölçüm cihazı LS'nin şiddeti kademeli arttırılan egzersiz testi sırasında test-tekrar test şeklindeki ölçümlerle güvenirliği belirlendi. Ayrıca BCL referans alındığında LS analizörünün geçerliliği karşılaştırılarak değerlendirildi.

LS ve BCL analizörlerinin güvenilirlik değerlendirmesinde SKK ve Pearson korelasyon katsayılarının benzer sonuçlar verdiği gözlendi. Her iki analizörün test-tekrar test şeklinde yapılan güvenilirlik çalışması sonuçları mükemmel uyum göstermekle birlikte, BCL'nin LS analizörüne göre daha uyumlu sonuçlar verdiği saptandı. Diğer el tipi cihazlar ile karşılaştırıldığında, bu çalışmada elde edilen güvenilirlik katsayıları benzerdir. Tanner ve ark. çalışmalarında benzer yöntemle ölçüm yapan farklı üç el analizörü için SKK değerlerini 0.910, -0.984 ve 0.988 olarak vermişlerdir. Aynı çalışmada el analizörleri için verilen varyasyon katsayısı olarak TH değerleri \%10.2, -\%5.7 ve \%8.5'dir. Üç analizörden biri LS olup verileri ilk sıradakilerdir (7). Hazır et al. ise LSplus analizörü için SKK değerini 0.998, Pearson korelasyon kat sayısını 0.994 , varyasyon katsayısı olarak TH değerini \% 4.9 olarak vermişlerdir (8). 
BCL analizörünün tüm konsantrasyon aralıklarındaki uyum değerleri birbirine bezerdi ve LS ile karşılaştırıldığında güvenilirlik sonuçları çok daha iyiydi. Dascombe ve ark. bir başka el analizörünün varyasyon katsayısı olarak TH değerlerini istirahatte \%7.3, orta yoğunluktaki egzersizde $(200 \mathrm{~W}) \% 9.6$ ve maksimal egzersizde \%3.1 şeklinde vermişlerdir. SKK değerleri ise istirahatte 0.97 , orta yoğunluktaki egzersizde 0.96 ve maksimal egzersizde 0.94 idi (9).

Bireylerin belli bir yoğunlukta yaptıkları egzersizde kan laktat konsantrasyonunun hangi düzeyde olacağı; bireyin aerobik kapasitesi, yaşı, kas lifi tipi, substrat miktarı, kafein kullanımı, bireyin antrenman durumu gibi birçok değişkenin etkisi altındadır $(10,11)$. Bu nedenle bireylerin değil, laktat analizörlerinin karşılaştırıldığ 1 bir çalışmada bireylere sabit bir yoğunlukta egzersiz yaptırmak yerine, laktat analizörlerinin ölçüm yaptığı sabit aralıkları değerlendirmek daha doğru olacaktır. Tanner ve arkl. LS analizörünün güvenirliğini $<4.0 \mathrm{mM}, 4.0-8.0 \mathrm{mM}$ ve $>8$ $\mathrm{mM}$ aralıklarında değerlendirmiş; $\mathrm{TH}$ ve varyasyon katsayısı olarak TH değerlerini sırasıyla 0.5 $\mathrm{mM}$ ve $-\% 19,0.3 \mathrm{mM}$ ve $-\% 3,8$ ve $1.1 \mathrm{mM}$ ve $\% 9,8$ bulmuşlardı ve en uyumlu sonuçlar 4.0-8.0 $\mathrm{mM}$ aralığı içindeydi (7).

Sonuçlar bu değerlerle uyumlu olmakla birlikte, bu çalışmada derişim aralıklarını $<2.5 \mathrm{mM}, 2.5$ $5.0 \mathrm{mM}$ ve $>5.0 \mathrm{mM}$ olarak belirlemiştik. Bunun nedeni bireysel anaerobik eșik değerinin literatürde 3.0-5.0 mM arasında hesaplanması ve ortalama $4.0 \mathrm{mM}$ olarak kabul edilmesidir. Bireysel anaerobik eşik değeri $4.0 \mathrm{mM}$ kan laktat düzeyinin altında veya üstünde olabilir (6). Bu nedenle analizörlerin 2.5-5.0 mM aralığındaki güvenilirlikleri değerlendirildi. Literatürde benzer nedenle aynı konsantrasyon aralıklarını kullanan çalışma bulunmaktadır (8).

Pyne ve ark. farklı bir el analizörünün tekrarlı ölçüm sonuçlarını Bland \& Altman yöntemi ile incelemiş ve ölçüm farklarına ilişkin ortalama değeri $0.08 \mathrm{mM}$, uyum sınırlarının alt limitini 0.52 üst limiti 0.68 bulmuşlardır (12). Bishop da farklı el ve laboratuvar analizörünün tekrarlı ölçüm sonuçları incelemiş; el analizörünün uyum sınırlarını alt limit -0.9 , üst limit -0.7 ; la- boratuvar temelli analizörün uyum sınırlarını alt limit -0.2 , üst limit 0.3 olarak saptamıştır (13). $\mathrm{Bu}$ değerler LS için elde edilen uyum sınırları ile uyumlu olmassına karşın, BCL analizörünün uyum sınırlarına ilişkin alt ve üst limitler arasındaki fark çok daha dar aralıktadır.

Tekrarlanabilirlik, aynı koşullarda aynı örnek üzerinde yapılan tekrarlı ölçümlerin birbirine yakınlığıdır ve güvenilirlik olarak tanımlanır. Bir ölçüm yönteminin kullanılabilir olup olmadığını değerlendirmede değerli olduğu gibi iki farklı ölçüm yöntemini karşılaştırırken de kullanılır (14). Güvenilirlik ölçüm yapılan analizörlerin uyumunu önemli ölçüde etkilemektedir. Eğer analizörlerden biri zayıf güvenirliğe sahipse iki analizör arasındaki uyumun zayıf olması kaçınılmazdır. Eğer referans analizörün güvenirliği düşükse değerlendirdiğimiz analizör çok iyi bir analizör olsa da uyum yüksek çlkmayacaktır. Eğer iki analizörün de güvenirliği düşükse sorun daha da büyüyecektir. Güvenilirlik çalışmalarında BCL analizörünün uyum sınırlarının dar bir aralıkta olduğu gözlenince, referans yöntem olarak kullanılmasının uygun olacağına karar verdik.

Kan laktat düzeylerinin regresyon analizi sonuçları değerlendirildiğinde, her iki analizör ile yapılan ölçümlerde elde edilen değerler arasında hem sistematik hem de orantısal yanlılık bulunduğu sonucuna varılmaktadır. “ $y=0.789 x+0.587$ " denklemi regresyon doğrusunu tanımlar. Bu denklem yardımıyla LS analizörü ile elde edilen konsantrasyon değerleri kullanılarak, referans yöntem olan BCL değerleri tahmin edilebilirse de, bu koşullarda iki analizör arasında mutlak uyumun iyi bir düzeyde olmadığını gösterir.

Bu çalışmada kullanılan referans analizör ile ölçülen kan laktat değerleri ile LS arasındaki yüksek korelasyon, LS analizörünün yüksek geçerliliği olduğunu gösterir. Bu çalışmada elde ettiğimiz korelasyon katsayısı ve TSH değerleri başka el analizörleriyle yapılan çalışmalardaki değerler ile benzerdir. Mc Noughton ve ark.'nın dört farklı el analizörü ile yapmış olduğu geçerlilik çalışmasında geniş bir konsantrasyon aralığındaki korelasyon katsayıları 0.948, - 
$0.955,-0.917$ ve 0.807 çlkmıștı (15). Baldari ve ark.'nın iki farklı el analizörü ile yaptıkları geçerlilik çalışmasındaki korelasyon katsayıları 0.990 ve 0.975 , TSH $0.33 \mathrm{mM}$ ve $0.55 \mathrm{mM}$ idi (16). Pyne ve ark.'nın bir el analizörü ile iki farklı laboratuvar kökenli analizörü karşılaştırarak yaptıkları geçerlilik çalışmasında ise korelasyon katsayıları 0.975 ve 0.991 bulunmuştu (12).

LS analizörünün geçerliliğine yönelik istatistik analizleri değişik konsantrasyon aralıklarında da değerlendirildi: $<2.5 \mathrm{mM}$ ve $>5.0 \mathrm{mM}$ kan laktat düzeyleri değerlendirildiğinde LS analizörü ve referans yöntem ölçümleri arasında orta düzey uyum olduğundan söz edilebilir. 2.5-5.0 mM aralığındaki kan laktat derişimi verileri değerlendirildiğinde ise LS analizörü ve referans yöntem ölçümleri arasında yüksek uyum varlığından söz edilebilir (Tablo 3).

LS analizörünün geçerliliğini değerlendirmek için yaptığımız KSH, SKK (mutlak uyum), SKK (tutarlılık) ve Pearson korelasyon katsayısı analizlerinin farklı konsantrasyon aralıklarındaki sonuçları değerlendirildiğinde tüm aralıklar için uyumlu olmakla birlikte, en uyumlu sonuçların 2.5-5.0 mM aralığında olduğu gözlendi. Tanner ve ark. üç farklı el analizörünü karşılaştırdıkları çalışmada yalnızca $8.0 \mathrm{mM}$ 'den yüksek laktat değerlerini referans yöntem olarak kullandıkları laboratuvar analizörü ile karşılaştırmışlardı. İlki LS için olmak üzere, sırası ile SKK, varyasyon katsayısı olarak KSH ve KSH değerlerini 0.837, $\% 11.9$ ve $-1.4 \mathrm{mM}$; $0.913,-\% 8,9$ ve $-1.1 \mathrm{mM}$; $0.936,-\% 7.4$ ve -0.9 mM bulmuşlardı (7). Bu değerler, bu çalışmada sunulan $>5.0 \mathrm{mM}$ kan laktat konsantrasyonu değerleri ile benzerdir. Ancak, LS analizörünün referans yönteme göre doğruluğu diğer iki el analizöründen daha düşük olduğu belirtilmektedir (7).

Hazır ve ark.nın LSplus analizörünü laboratuvar kökenli bir analizör ile karşılaştırarak yaptıkları geçerlilik çalışmasında farklı konsantrasyon düzeylerindeki korelasyon katsayıları $<2.5 \mathrm{mM}$ değerleri için 0.907, 2.5-5.0 mM aralığı için 0.925 ve $>5.0 \mathrm{mM}$ değerleri için $0.994 \mathrm{mM}$ idi. LSplus analizörü geçerliliği ve güvenirliği yüksek bir analizör olarak belirtilmektedir. Ancak,
$<2.5 \mathrm{mM}$ ve $>5.0 \mathrm{mM}$ kan laktat konsantrasyonu değerlerinde bu analizörün düzeltme faktörü ile birlikte kullanılması önerilmektedir (8).

Geçerlilik çalışmalarında SKK ve Pearson korelasyon katsayısı yaygın olarak kullanılan yöntemlerdir. Bununla birlikte, bu yöntemler geçerliliği sorgulanan yöntem ile referans yöntem arasındaki sistematik farklılıkları belirlemede kullanışlı değildir. Değişik kan laktat konsantrasyon aralıkları için elde ettiğimiz bulgular da aynı sonucu doğrular niteliktedir. LS analizöründe $>5.0 \mathrm{mM}$ kan değerleri ile referans yöntem arasında sırasıyla SKK (tutarlılık) için 0.783'lük, Pearson korelasyon katsayısı için 0.841 'lik orta düzeyde korelasyon elde edilmekle birlikte, Bland \& Altman yöntemi ile değerlendirildiğinde LS analizöründe ölçülen değerler referans yöntemle ölçülen değerlerden sistematik olarak önemli derecede düşük bulundu (Şekil 4). Konsantrasyon değerlerinin farklarına ait ortalama $-0.878 \mathrm{mM}$, uyum sinırları ise 0.864 ve -2.621 olarak bulundu. Bu bulgular yüksek kan laktat düzeylerinde LS analizörünün referans yöntem yerine kullanılamayacağını göstermektedir. Kullanılması halinde $>5.0 \mathrm{mM}$ değerleri için düzeltme faktöründen yararlanılmalıdır.

Bu çalışmanın sonuçları LS ve BCL analizörlerinin yüksek güvenirliği olduğunu göstermektedir. İki analizör arasında bir karşılaştırma yapıldığında BCL'nin daha yüksek güvenirliği olduğu gözlenmektedir. LS analizörünün güvenilirlik sonuçları değiş̧ik marka el analizörlerinin literatürdeki sonuçları ile karşılaştırıldığında benzer oldukları anlaşılmaktadır. LS analizörünün güvenilirliği farklı konsantrasyon aralıklarında değerlendirildiğinde en uyumlu sonuçların $>5.0 \mathrm{mM}$ düzeylerinin yanı sıra hemen hemen yakın sonuçların elde edildiği 2.5$5.0 \mathrm{mM}$ aralığında olduğu gözlenmektedir. BCL analizörünün de güvenirliği farklı konsantrasyon aralıklarında değerlendirildiğinde, tüm konsantrasyon aralıkları için mükemmel uyum gösterdiği belirlendi.

LS analizörünün geçerlilik çalışmasında referans yöntem olarak BCL analizörü kullanıldığı bu çalışmada sonuçlar, LS'nin yüksek geçerliğe sahip olduğunu desteklemektedir. LS analizörü- 
nün geçerlilik sonuçları literatürdeki değişik marka el analizörlerinin geçerlilik sonuçları ile benzer çıktı. Geçerlilik farklı konsantrasyon aralıklarında değerlendirildiğinde en uyumlu sonuçların 2.5-5.0 mM aralığında olduğu gözlendi. LS analizörünün $<2.5 \mathrm{mM}$ ve $>5.0 \mathrm{mM}$ düzeyleri için yapılan geçerlilik değerlendirmesinde orta düzeyde uyum belirlendi. $>5 \mathrm{mM}$ düzeylerinde LS analizöründe ölçülen değerler referans yöntemle ölçülen değerlerden sistematik olarak önemli derecede düşük bulundu. LS analizörünün yüksek konsantrasyon değerlerinde kullanımının uygun olmadığı ve referans yöntemle birbirinin yerine kullanılamayacağı sonucuna varıldı. Kullanılması halinde $>5.0 \mathrm{mM}$ düzeylerinde düzeltme faktöründen yararlanılması önerilebilir. Buna karşın, LS analizörü $<5.0 \mathrm{mM}$ kan laktat konsantrasyonu değerlerinde bir düzeltme faktörü olmaksızın kullanılabilir.

*Bu çalışma Süleyman Demirel Üniversitesi Bilimsel Araştırma Projeleri Koordinasyon Birimi tarafindan 3197-TU1-12 proje no ile desteklenmiștir.

\section{KAYNAKLAR}

1. Almarwaey OA, Jones AM, Tolfrey K. Maximal lactate steady state in trained adolescent runners. J Sports Sci. 2004;22(2):215-25.

2. Tanaka $\mathrm{K}$, Watanabe $\mathrm{H}$, Konishi $\mathrm{Y}$, et al. Longitudinal associations between anaerobic threshold and distance running performance. Eur J Appl Physiol Occup Physiol. 1986;55(3):248-52.

3. Jacobs I. Blood lactate. Implications for training and sports performance. Sports Med. 1986;3(1): 10-25.

4. Burfeind 0 , and Heuwieser W. Validation of handheld meters to measure blood L-lactate concentration in dairy cows and calves. J Dairy Sci. 2012;95(11):644956.

5. Hopkins WG. Measures of reliability in sports medicine and science. Sports Medicine. 2000;30(1): 1-15.

6. Heck H, Mader A, Hess G, et al. Justification of the 4mmol/l lactate threshold. Int $J$ Sports Med. 1985;6(3):117-30.

7. Tanner RK, Fuller KL, Ross ML. Evaluation of three portable blood lactate analysers: Lactate Pro, Lactate Scout and Lactate Plus. Eur J Appl Physiol. 2010;109(3):551-9.

8. Hazır T, Aşçı A, Cinemre A, et al. Evaluation of a handheld lactic acid analyser: reliability and validity of the Lactate Scout (+).Hacettepe J Sport Sci. 2010;21(3):79-89.

9. Dascombe BJ, Reaburn PR, Sirotic AC, et al. The reliability of the i-STAT clinical portable analyser. J Sci Med Sport. 2007;10(3):135-40.

10. Goodwin ML, Harris JE, Hernández A. Blood lactate measurements and analysis during exercise: a guide for clinicians. J Diabetes Sci Technol. 2007;1(4):55869.

11. Gökbel H, Okudan N. Egzersize kan laktat cevabını etkileyen faktörler. Genel Tıp Der. 2000;10(3): 135-43.

12. Pyne DB, Boston T, Martin DT, et al. Evaluation of the Lactate Pro blood lactate analyser. Eur J Appl Physiol. 2000;82(1-2):112-6.

13. Bishop D. Evaluation of the Accusport lactate analyser. Int J Sports Med. 2001;22(7):525-30.

14. Bland JM, Altman DG. Statistical methods for assessing agreement between two methods of clinical measurement. Lancet. 1986;327(8476):307-10.

15. Mc Naughton LR, Thompson D, Philips G, et al. A comparison of the Lactate Pro, Accusport, Analox GM7 and Kodak Ektachem Lactate Analysers in normal, hot and humid conditions. Int J Sports Med. 2002;23(2):130-5.

16. Baldari C, Bonavolontà V, Emerenziani GP, et al. Accuracy, reliability, linearity of Accutrend and Lactate Pro versus EBIO plus analyser. Eur J Appl Physiol. 2009;107(1):105-11. 